\title{
Mitral valve regurgitation and endocarditis triggered by a needle
}

\author{
Chuanzhen Liư ${ }^{1,2}$, Yan Liư ${ }^{3}$, Jianhua $\mathrm{Li}^{1}$ and Guangqing Cao ${ }^{1 *} \mathbb{B}$
}

\begin{abstract}
Background: Cardiac foreign bodies are extremely rare in clinical patients, especially when foreign bodies damage the internal structure of the heart coincidentally after they penetrate the heart.

Case presentation: Here, we report the case of a two-year-old girl whose heart was penetrated by a needle, which triggered mitral valve regurgitation and endocarditis. After a comprehensive inspection, accurate judgment and surgical preparation, we removed the needle and repaired her mitral valve. Fortunately, she recovered postoperatively.

Conclusion: From this case, we can know that when cardiac foreign bodies are suspected, ultrasound is an important inspection method. Moreover, the approaches for handling each such case are different depending on the associated injuries.
\end{abstract}

Keywords: Endocarditis, Heart failure, Needle, Edge to edge, Case report

\section{Background}

Cardiac foreign bodies are extremely rare in clinical patients [1], and metallic foreign bodies are most reported [2]. They mostly occur in the right ventricle, and this may be related to the anatomical position of the right ventricle. These foreign bodies mostly enter from the left anterior chest close to the sternal stem. Some foreign bodies can also flow into the right heart cavity from the peripheral vein [3]. However, most patients have no typical symptoms and signs.

Because the heart is an organ of continuous movement, trauma resulting from metal foreign bodies remaining in the heart can not only cause hemorrhage and shock but also cause pericardial effusion and even pericardial tamponade, resulting in unpredictable serious consequences, and therefore should be highly regarded. The foreign bodies can sometimes be directly removed by minimally

\footnotetext{
*Correspondence: caogq001@163.com

${ }^{1}$ Department of Cardiovascular Surgery, Qilu Hospital of Shandong University, Wenhua Xi Road 107\#, Jinan 250012, Shandong Province, People's Republic of China

Full list of author information is available at the end of the article
}

invasive surgery [4]. However, if a foreign body destroys the valves and subvalvular structure of the heart, it can cause heart failure and endocarditis. Therefore, it needs to be paid high attention to and should be treated with thoracotomy under cardiopulmonary bypass. Herein, we present the case of a two-year-old girl with mitral valve regurgitation and endocarditis triggered by a needle.

\section{Case presentation}

A two-year-old girl was brought to the emergency room because of shortness of breath and chest distress (History of present illness seen Table 1). However, the hemodynamics including heart rate and blood pressure were stable. She also had an intermittent fever for the past one month, and the highest was $39^{\circ} \mathrm{C}$. A $3 / 6$ grade systolic murmur was heard at the apex auscultation area. ECG was nearly normal. Chest X-ray and thoracic CT showed a needle inserted from the chest wall into the heart cavity (Figs. 1 and 2). Echocardiography showed severe mitral valve prolapse and regurgitation (Fig. 3A, Additional file 1: Video 1); the needle was inserted into the left ventricle and papillary muscle (Fig. 3B, Additional file 2: Video 2). We asked the patient's parents 


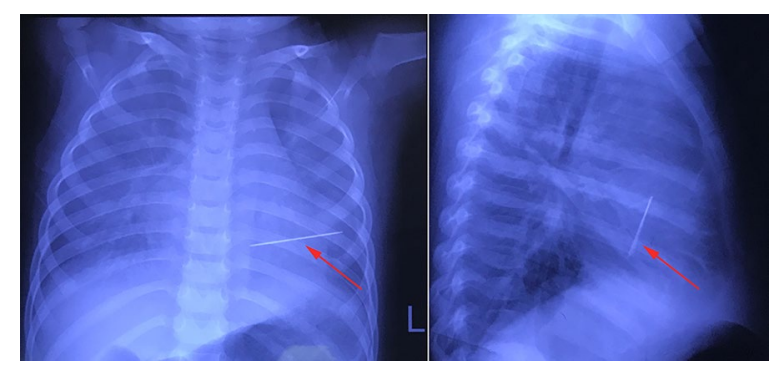

Fig. 1 Chest X-ray. Arrows indicated the needle

about the medical history of the child; however, they were unaware of how the needle was penetrated the girl's body. After the exclusion of surgical contraindications, we decided to perform this operation. After thoracotomy, we found that the left ventricular surface had severe hyperplasia and adhesion to the pericardium. However, the needle was invisible. We then established a cardiopulmonary bypass (CPB). After cardiac arrest, we observed that the apex of the needle penetrated from the right atrium-atrial septum into the posterior wall of the left ventricle through the anterior papillary muscle. Anterior papillary muscle and chordae tendineae were partially destroyed and showed infectious endocarditis-associated changes. The mitral valve was severely refluxed. We took the needle out from the mitral orifice (Fig. 4B) and fixed the chordae tendineae to the papillary muscle. However, some chordae tendineae and papillary muscles were destroyed, and moderate-to-severe mitral valve regurgitation persisted. Accordingly, we repaired the mitral valve by double-orifice (edge-to-edge) technique (Fig. 4A). Intraoperative transesophageal echocardiography (TEE) showed mild mitral valve regurgitation (Additional file 3: Video 3). Finally, we separated the left ventricular surface from the pericardium and closed the crevasse by a mattress suture using a felt pledget (Fig. 4C, D). Finally, the girl recovered and was discharged 26 days after the operation. The child was already treated with antibiotics before coming to the hospital, and preoperative blood cultures were negative. However, endocarditis could be diagnosed by 1 major criteria (imaging positive for IE) and 3 minor criteria (predisposition, fever defined

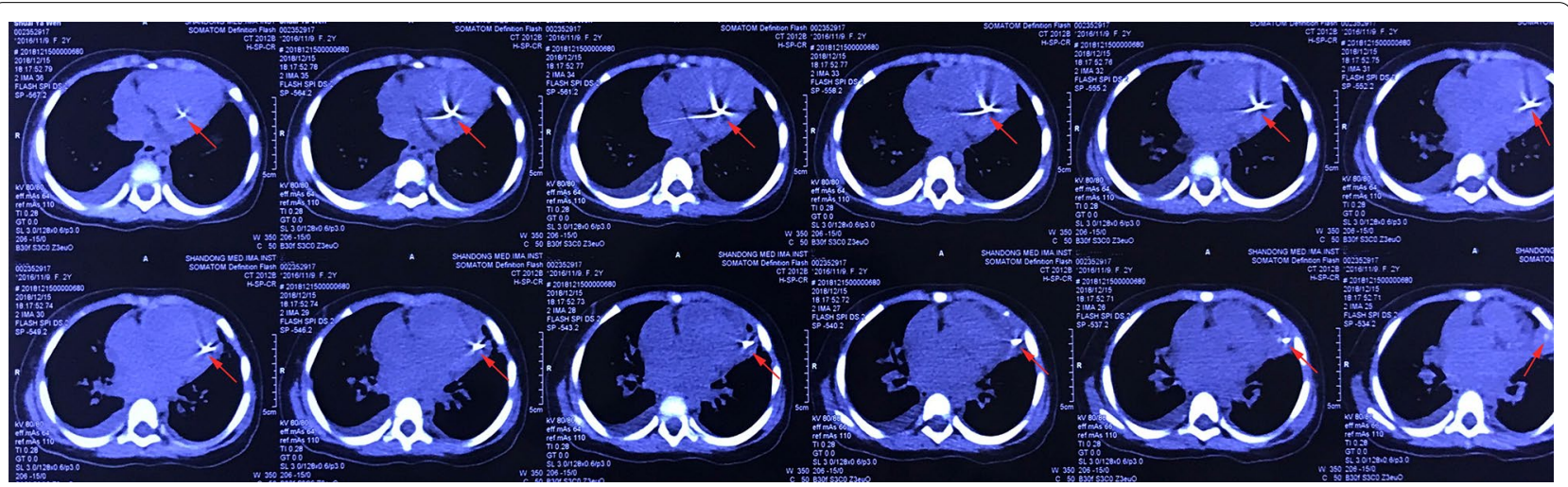

Fig. 2 High-quality thoracic CT. Arrows indicated the entry, exit and extension of the needle through the heart
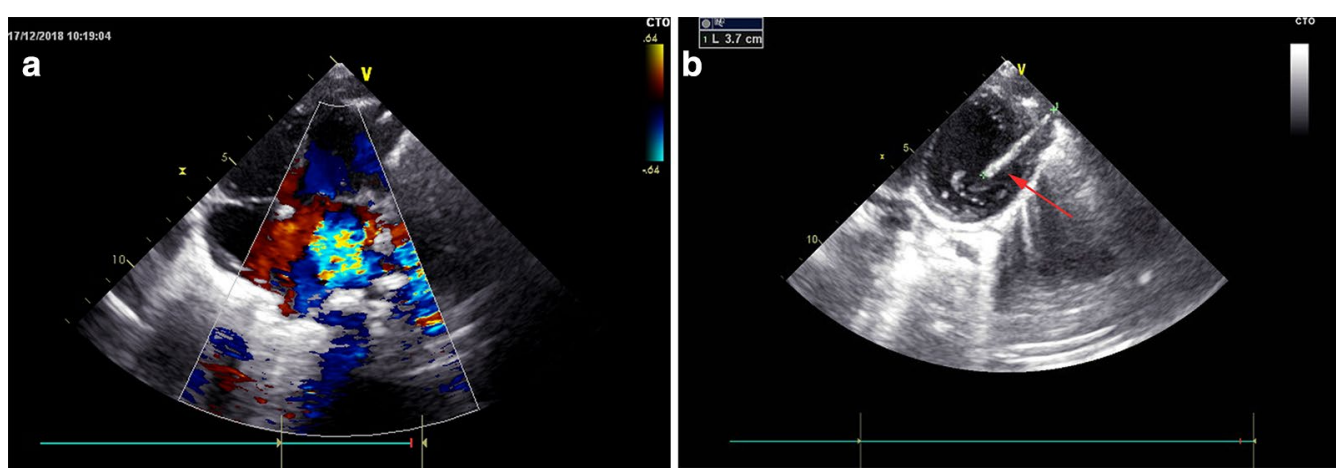

Fig. 3 Echocardiography. A Echocardiography showed severe mitral valve regurgitation. B Echocardiography showed the needle in the heart cavity. The arrow indicated the needle 

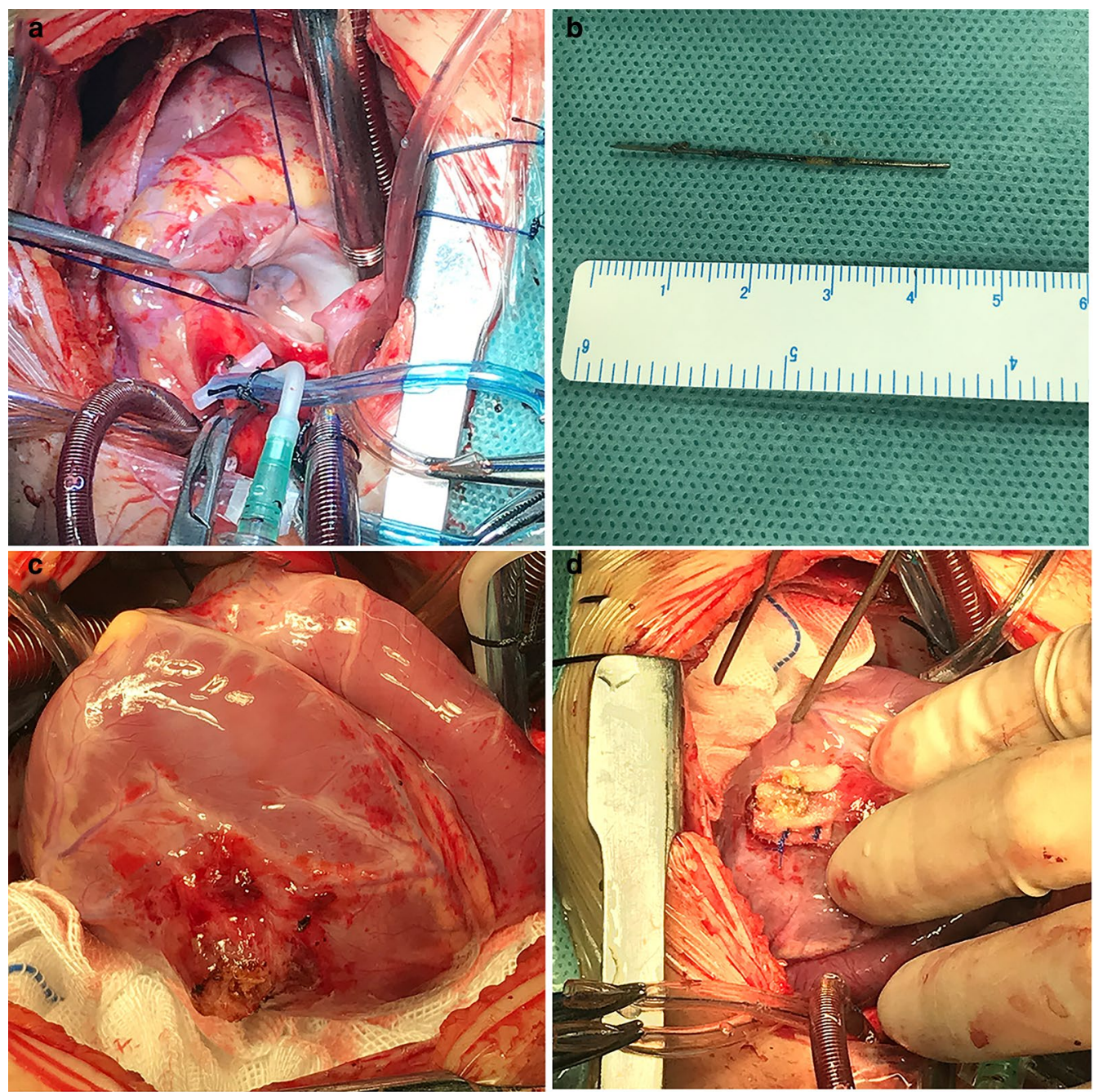

Fig. 4 Imaging of the operation. A mitral valve was repaired by double-orifice (edge to edge) technique, and no regurgitation. $\mathbf{B}$ the needle removed from the heart. C Adhesion of left ventricular and pericardium. D Close crevasse with felt piece

Table 1 The time line table of the girl's symptoms and sign

\begin{tabular}{ll}
\hline Time line & Symptoms and sign \\
\hline Uncertain time & The needle was penetrated the girl's body \\
One month & Intermittent fever \\
$2 \mathrm{~h}$ & Sudden shortness of breath and chest distress \\
Present & Come to the emergency room \\
\hline
\end{tabular}

as temperature $>38^{\circ} \mathrm{C}$ and vascular phenomena) according to 2015 ESC Guidelines for the management of infective endocarditis. As a result, diuretics were used within 2 months after the operation, and antibiotics were used because of endocarditis according to the ESC guidelines of infective endocarditis. Fortunately, she was well at the 2-year follow-up. Echocardiography at the local hospital showed that mitral valve was normal, but she did not come to our hospital for echocardiography examination due to the long distance and economic reasons. Nonetheless, close attention must be paid to the fragile mitral valve as the girl grows. There have been previous reports of a heart stuck by a needle; however, reports on the damage of the papillary muscles and chordae tendineae are rare.

\section{Discussion and conclusions}

Some cases of cardiac foreign bodies have been reported previously. There are various types of foreign bodies such as needles [5], bullets [6], a fish thorn [7], and a catheter [8] among others. The foreign bodies may penetrate different parts of the heart, and the most commonly reported part is the right ventricle 
which is at the anterior of the heart. Other parts include the left ventricle, left atrium, right atrium, and pulmonary artery. Whether the cardiac foreign bodies need to be removed through operation depends on the symptoms and possible complications.

The method of surgery for removing metal foreign bodies from the heart is difficult and time intensive but very crucial. With the development of medical equipment and technological advancements, ultrasound has become the main basis for clinically determining the location of foreign bodies [9]. It can determine the location of foreign bodies with an accuracy that traditional X-ray and high-resolution CT cannot achieve. Foreign bodies in the heart are different from foreign bodies in other organs, and once the diagnosis is made, require surgical treatment as soon as possible to remove the foreign bodies to avoid complications such as infection, bleeding, and embolism [10]. In patients with pericardial effusion, irrespective of whether pericardial tamponade occurs, prompt treatment should be conducted as soon as possible to avoid hemodynamic disorders, which can lead to the death of the patient. Once a pericardial tamponade is found, emergency thoracotomy should be performed quickly and decisively. Further, even for those without signs of cardiac tamponade, the foreign body should be removed by early surgery to avoid secondary symptoms. In our case, ultrasound, X-ray, and high-resolution CT were all used. There was no pericardial tamponade. However, ultrasound determined that the needle was in the heart cavity and had destroyed the mitral valve with severe mitral valve regurgitation. The girl showed symptoms of left-sided heart failure.

The surgical approach for the removal of the foreign bodies is individualized based on the types of foreign bodies [9]. It is mostly influenced by the location of the foreign bodies in the heart and the associated injuries caused by foreign bodies. When the foreign bodies are inserted into the cavity of the heart and influence important structures such as the papillary muscle or valve, and especially if endocarditis is observed, $\mathrm{CPB}$ is needed. Our case was very rare, wherein the needle penetrated from the intercostal space to the left ventricle and then inserted into the papillary muscle simultaneously. The girl had a fever, shortness of breath, and chest distress because of mitral valve regurgitation and endocarditis. We could not see the head of the needle from the outside of the heart after thoracotomy, and $\mathrm{CPB}$ was therefore necessary. With the help of $\mathrm{CPB}$, we could remove the needle from inside the heart cavity. We then successfully repaired the mitral valve, and the girl's symptoms disappeared.

\section{Conclusion}

Cardiac foreign bodies, especially a needle, are very rare, and ultrasound is an important inspection method. The approaches to handle these are different depending on the associated injuries.

\section{Abbreviations}

CPB: Cardiopulmonary bypass; TEE: Transesophageal echocardiography.

\section{Supplementary Information}

The online version contains supplementary material available at https://doi. org/10.1186/s12872-021-02109-z.

Additional file 1. Preoperative Echocardiography showed severe mitral valve prolapsed and regurgitation.

Additional file 2. Preoperative Echocardiography showed the needle in the heart cavity.

Additional file 3. Intraoperative Transesophageal Echocardiography (TEE) showed mild mitral valve regurgitation, and no mitral valve stenosis.

\section{Acknowledgements}

We express our sincere thanks to Dr. Xiquan Zhang and Dr. Shuming Wu for thoughtful discussion and valuable comments.

\section{Authors' contributions}

LCZ collected the data and wrote the manuscript. LY do introperative TEE. CGQ was Chief surgeon and LJH was assistant. The authors read and approved the final manuscript.

\section{Funding}

This work was supported by the Shandong Provincial Natural Science Foundation of China (no. ZR2019PH024). Medical Health Technology Development Plan of Shandong province. (no. 2016WS0353). Both of funders provided the financial support.

\section{Availability of data and materials}

Not applicable.

\section{Declarations}

Ethics approval and consent to participate

Not applicable.

\section{Consent for publication}

The authors confirm that written consent for submission and publication of this case report, including the images and the associated movie, has been obtained from the patient's parents. A copy of the written consent is available for review by the Editor-in-Chief of this journal.

\section{Competing interests}

Authors have no competing interests associated with this study.

\section{Author details}

${ }^{1}$ Department of Cardiovascular Surgery, Qilu Hospital of Shandong University, Wenhua Xi Road 107\#, Jinan 250012, Shandong Province, People's Republic of China. ${ }^{2}$ Pantheum Biotechnology Co., Ltd, Jinan, Shandong Province, People's Republic of China. ${ }^{3}$ Department of Cardiology, Qilu Hospital of Shandong University, Wenhua Xi Road 107\#, Jinan 250012, Shandong Province, People's Republic of China.

Received: 15 March 2021 Accepted: 8 June 2021

Published online: 13 June 2021 


\section{References}

1. Leitman $M$, Vered Z. Foreign bodies in the heart. Echocardiography. 2015;32:365-71

2. Wang $X$, Zhao $X$, Du D, et al. Management of metallic foreign bodies in the heart. J Card Surg. 2012;27:704-6.

3. Danek BA, Kuchynka P, Palecek T, et al. Needle fragment embolism into the right ventricle: a rare cause of chest pain case report and literature review. Wien Klin Wochenschr. 2016;128:215-20.

4. Qian $\mathrm{H}$, Song H, Li Y, et al. Removal of metallic foreign body in heart by minimally invasive procedure under the guidance of transesophageal echocardiography and transthoracic echocardiogram. J Thorac Dis. 2015;7:E560-3.

5. Al-Musawi M, Rubay D, Ohanisian L, et al. An unusual presentation of a cardiac foreign body in a pediatric patient. Cureus. 2019;11:e4829.

6. Yoon B, Grasso S, Hofmann LJ. Management of bullet emboli to the heart and great vessels. Mil Med. 2018;183:e307-13.
7. Zhang X, Wei X, Rao L, et al. A rare case of cardiac foreign body. Eur Heart J. 2019;40:1800

8. Peng J, Zhang XM, Yang $L$, et al. A novel two-step technique for retrieving fractured peripherally inserted central catheter segments migrating into the heart or the pulmonary artery. Biomed Res Int. 2016; 2016: 7814529.

9. Fry SJ, Picard MH, Tseng JF, et al. The echocardiographic diagnosis, characterization, and extraction guidance of cardiac foreign bodies. J Am Soc Echocardiogr. 2000;13:232-9.

10. Actis Dato GM, Arslanian A, Di Marzio P, et al. Posttraumatic and iatrogenic foreign bodies in the heart: report of fourteen cases and review of the literature. J Thorac Cardiovasc Surg. 2003;126:408-14.

\section{Publisher's Note}

Springer Nature remains neutral with regard to jurisdictional claims in published maps and institutional affiliations.
Ready to submit your research? Choose BMC and benefit from:

- fast, convenient online submission

- thorough peer review by experienced researchers in your field

- rapid publication on acceptance

- support for research data, including large and complex data types

- gold Open Access which fosters wider collaboration and increased citations

- maximum visibility for your research: over $100 \mathrm{M}$ website views per year

At $\mathrm{BMC}$, research is always in progress.

Learn more biomedcentral.com/submissions 